\title{
presentación
}

\section{INVESTIGACIÓN Y PASTORAL: ¿DIVORCIO NECESARIO O CONVENIENTE SIMBIOSIS?}

A poco tiempo de celebrarse los cuarenta años de Allpanchis Phuturinqa, parece conveniente y hasta necesario hacer un balance de la trayectoria recorrida, un ejercicio de toma de conciencia similar al realizado años atrás por el P. Manuel Marzal S.J., reconocido antropólogo a quien le fue confiado hacer una reseña de la investigación andina a los veinte años de nuestra revista. En dicha ocasión, Marzal ya ponía sobre relieve la necesidad de recuperar los estudios sobre la religión andina "[...] por cierta fidelidad al carisma fundacional de los obispos del sur andino que querían conocer mejor la religión y la cultura andinas para poder realizar mejor su trabajo pastoral». ${ }^{1}$ Según el prestigioso

1. Manuel Marzal. "La investigación de la religión andina". Allpanchis Phuturinqa, año 21, n. ${ }^{\circ} 34$, segundo semestre, 1989, p. 26. 
antropólogo, que perteneció al grupo fundacional de Allpanchis, el Instituto de Pastoral Andina (IPA) debía recuperar su espíritu originario para convertirse en una "plataforma de diálogo para científicos sociales, teólogos y agentes de pastoral\%.

Veinte años después, esta preocupación parece estar viva y latente no solo por la disminución y subsecuente escasez de estudios dedicados a la temática religiosa andina, sino porque hoy parece ser evidente la necesidad de cierta interacción entre investigación y pastoral.

En efecto, Allpanchis debe su existencia a la iniciativa de varios obispos que consideraron útil y conveniente la creación de una entidad dedicada al estudio académico de la región andina: el IPA. La importancia de la pastoral en la misión institucional del IPA resulta obvia ya desde su nombre. La lógica subyacente en tal iniciativa era comprender mejor el mundo andino para poder evangelizarlo. Por ello muchos de los artículos en los primeros números de Allpanchis buscaban describir y comprender ese mundo $\mathrm{y}$, al mismo tiempo, establecer reflexiones teológicas sobre estos estudios.

Podría objetarse que desde una perspectiva académica no hay relación posible entre investigación y pastoral, pues los estudios andinos tienen autonomía en relación con los fines pastorales precisamente para lograr objetividad en la investigación. Esta argumentación no carece de fundamento 
teniendo en cuenta que el mundo académico necesita libertad para ejecutar adecuadamente su tarea: el ejercicio de la búsqueda de la verdad supone siempre libertad intelectual.

Sin embargo, también es cierto que el propio ejercicio académico supone considerar la integralidad del fenómeno religioso, de modo que se logre una mayor objetividad al evitar reducir metodológicamente la religión a un mero ejercicio subjetivo desprovisto a priori de su dimensión trascendente. En la cuestión religiosa, hoy se ve necesario remitirse nuevamente al hecho cristiano, más allá de triunfalismos o criticismos excesivos, y tomar en cuenta lo espiritual como fenómeno objetivo. Más allá de sincretismos reales y desafiantes, el hecho religioso cristiano andino es un fenómeno tan macizo que ni siquiera los marxistas -a pesar de sus interpretaciones que vacian de contenido católico las expresiones religiosas populares- osaron negarlo.

Así, pues, existen ciertas preguntas formuladas al mundo religioso andino que es posible responder a partir de la experiencia espiritual de los pobladores y de los evangelizadores, y que contribuyen a su mejor intelección: ¿Cómo explicar el contundente hecho religioso de la llamada religiosidad popular católica andina?, ¿cómo saber si la religión andina contiene o no elementos católicos acordes con la universalidad de la Iglesia?, ¿cómo determinar el peso del sincretismo en las comunidades andinas locales?, ¿cómo 
conocer la pervivencia de ritos precristianos o la adhesión interior de los feligreses indigenas al mensaje católico? La experiencia académica de varias décadas de debate en torno al problema de la religión en el mundo andino enseña que muchas de las respuestas a tales interrogantes parecen encontrarse en el terreno pastoral, es decir, en la experiencia práctica de los agentes pastorales que lidian con los problemas religiosos de estos pobladores, así como en la respuesta religiosa de estos últimos a tales propuestas evangelizadoras. En otras palabras, la pastoral parece ser una forma privilegiada de contrastar los estudios académicos con la religión real andina.

Paradójicamente, sin embargo, algunas veces la pastoral en estas regiones se ha ido vaciando de su contenido fundamental: la referencia a la persona de Jesucristo. Las preocupaciones pastorales en muchas zonas andinas acabaron por convertirse en mera acción social comprometida - muy a tono con las ideologías de moda en los setenta y ochenta- o terminaron absorbidas por reflexiones sociopolíticas. La propia acción evangelizadora - catequética y sacramental- fue calificada como invasiva o violenta en sí misma, y la enseñanza social de la Iglesia, descalificada.

Aquí es preciso señalar otro fenómeno importante ocurrido en las referidas décadas: los estudios andinos -especificamente su metodologia y, si cabe, su praxis transformadora - a veces han influido y afectado hondamente la pastoral. Los proyectos pastorales del sur andino 
elaborados en los setenta y ochenta -y que extienden sus influjos hasta la presente década- permiten percibir que la concepción de la pastoral se redefinió en términos sociológicos o políticos; en muchos casos pasó a ser entendida solo como concientización, por parte de las clases oprimidas, de su condición de dependencia y opresión. El enfoque sociológico, con sus matrices epistemológicas diversas pero que comparten la voluntad de inmanencia y no la fe, se volvió así el punto de referencia de la pastoral, su eje y su referente de medición y evaluación.

La pastoral así teórica y prácticamente reducida ha tenido mucho impacto en los agentes pastorales directos pero - hay que admitirlo después de cuarenta años- poco en el pueblo al cual estaba dirigida. Las expectativas sociopoliticas de muchos en las comunidades eclesiales de base parecen haber menguado considerablemente o, por lo menos, haberse replanteado después de muchos años de trabajo pastoral. Es más, la falta de una atención directa a las necesidades espirituales de la población parece estar directamente relacionada con el éxodo de los católicos surandinos a diversas denominaciones evangélicas. Por otro lado, la falta de capacidad para relacionar ambos fenómenos solo se explica por el enfoque epistemológico inmanentista con el que a veces se han llevado a cabo los estudios andinos.

A pesar de todo, los pobladores surandinos continúan abiertos a una pastoral explícitamente abierta a la 
dimensión espiritual de la persona. La experiencia reciente de agentes pastorales profundamente involucrados con el trabajo evangelizador catequético y sacramental en pueblos remotos demuestra que existen una sed de Dios y un hambre de lo espiritual que parecen pasar totalmente inadvertidos en muchos de los trabajos académicos. En Macusani cien misioneros llegaron a realizar casi mil bautismos, para complacencia de los pobladores nativos; en Ayaviri recientemente cerca de trescientos jóvenes decidieron por voluntad propia prepararse y recibir el sacramento de la confirmación.

La experiencia también demuestra que el trabajo evangelizador catequético, sacramental y espiritual no está reñido con las preocupaciones por la promoción humana de la población ni con la acción solidaria en favor de los más necesitados, los pobres y oprimidos, como lo demuestran los actuales proyectos desarrollados en salud, educación, alimentación básica y desarrollo económico de pequeñas empresas. Más de un misionero catequista habla hoy con convicción del hambre de pan y del hambre de Dios que permanecen en el corazón del poblador andino, hambres a los que ya el propio Juan Pablo II hizo referencia durante su visita a los pueblos del Perú.

Ello no deberia sorprender si se considera que incluso dentro de los círculos vinculados a la teología de la liberación existen hoy críticas en el sentido de volver a encantar el mundo, atendiendo incluso a la sensibilidad del 
hombre moderno tras la desmitologización racionalista de las décadas pasadas. Los más agudos incluso comienzan a afirmar que ante la indiferencia social del hombre hodierno es necesario recuperar una vida espiritual que impulse a la preocupación por los más pobres y a recobrar cierto sentido de identidad católica frente a un relativismo que se encuentra presente también en algunos ambientes teológicos y pastorales.

Hoy, pues, parece ser evidente que si bien la preocupación pastoral no debe disociarse de la investigación académica, tampoco los estudios andinos sobre religión pueden disociarse de la experiencia pastoral. Por ello el IPA considera actualmente que las dos líneas fundamentales de trabajo son la investigación sobre el mundo religioso de los Andes y la praxis pastoral en la realidad del sur andino peruano, que hoy tiene el desafío de hacer más efectivo el anuncio del Evangelio y contribuir a la integral promoción humana, especialmente de los pobres y marginados.

Con este espíritu de mutua colaboración entre pastoral e investigación y de manifiesta recuperación del estudio de la temática religiosa, hemos querido iniciar una estructura de secciones que dé cabida a trabajos etnográficos, históricos, sociológicos, antropológicos, artísticos o filosófico-teológicos relacionados con el mundo andino.

Con este número de carácter conmemorativo, con miras a los cuarenta años de Allpanchis, comenzamos la reedición 
de algunos trabajos memorables publicados en nuestra revista, que manifiestan claramente la posibilidad real de convergencia entre los estudios andinos y las necesidades pastorales. Las dificultades de acceso a tales trabajos debido al limitado número de ejemplares originales y la oportunidad de volverlos a presentar con un renovado trabajo editorial muestran la conveniencia de ponerlos a disposición del mundo académico, eclesial y de quien esté interesado en el mundo andino.

Por ello presentamos en este número el recordado artículo de Manuel Marzal sobre el proceso de cristianización del indígena peruano. Fundado en fuentes primarias y abordando de manera genérica pero profunda el largo e intenso proceso de evangelización en el mundo andino, el trabajo de Marzal constituye una excelente muestra del contexto fundacional de Allpanchis.

Con el propósito de recuperar la temática religiosa, publicamos también un par de artículos relacionados con la historia de la evangelización. El trabajo de Giuliana Miranda Larco entronca muy bien con el interés suscitado en años recientes por las misiones y los textos catequéticos, muy en la línea de la historia cultural reciente. Se trata de un trabajo histórico que devela la vida misionera de un clérigo criollo, fray Luis Jerónimo de Oré, nacido en Huamanga e hijo de un encomendero, que evangelizó en muchos lugares de América y redactó dos importantísimos textos que fueron ampliamente divulgados entre los misioneros. En el 
segundo artículo histórico, Álvaro Espinoza de la Borda, investigador ampliamente familiarizado con archivos eclesiásticos arequipeños, ofrece un estudio inédito sobre un colegio apostólico de Propaganda Fide en Arequipa, en el cual muchos religiosos con vocación misionera recibieron preparación espiritual para su labor evangelizadora en el altiplano en el siglo XIX.

El cientista social Alejandro Estenós Loayza, autor de varios trabajos concernientes a la relación entre cultura y desarrollo en América Latina, nos presenta una reseña crítica sobre los proyectos de desarrollo en los países latinoamericanos en décadas pasadas. Estenós busca develar los supuestos teóricos subyacentes respecto a la relación desarrollo-cultura. Para el autor, la cultura sería el gran elemento olvidado en las teorías del desarrollo aplicadas a América Latina, lo que ha tenido un evidente impacto en las políticas gubernamentales nacionales y en los proyectos de desarrollo en las zonas andinas.

El estilo barroco tiene la particularidad de haber marcado un cierto estilo evangelizador y, a la vez, haber confluido hondamente con el espíritu religioso del poblador andino. Con muchos años de experiencia en la gestión cultural y promoción del arte, Franz Grupp expone aquí un trabajo sobre la teatralidad del barroco en el Perú.

Finalmente, el filósofo y psicólogo Pablo Lego evidencia los supuestos filosóficos asociados con las teorías sociales 
utilizadas para el estudio del mundo andino. Tomando como punto de referencia fundamental las constantes metafísicas expuestas alguna vez por Étienne Gilson, Lego intenta develar las bases epistemológicas subyacentes a los estudios andinos en términos de realismo e inmanentismo filosóficos.

Esperamos que esta edición de Allpanchis entronque con la intención primaria de los pastores que fundaron el IPA, quienes no dudaron en promover con entusiasmo los estudios académicos sobre el mundo religioso andino con las herramientas y métodos de investigación de las modernas ciencias sociales.

El editor 